\title{
Risk Factors for Acute Exacerbation of Chronic Obstructive Pulmonary Disease in Industrial Regions of China: A Multicenter Cross-Sectional Study
}

This article was published in the following Dove Press journal: International Journal of Chronic Obstructive Pulmonary Disease

\author{
Hongna Dongl,* \\ Yuqiu $\mathrm{HaO}^{\mathrm{I}, *}$ \\ Dapeng $\mathrm{Li}^{2}$ \\ Zhenzhong Su' \\ Wei $\mathrm{Li}^{\prime}$ \\ Bingqing Shi ${ }^{1}$ \\ Peng Gao (D') \\ 'Department of Respiratory Medicine, \\ Second Hospital of Jilin University, \\ Changchun, Jilin Province, People's \\ Republic of China; ${ }^{2}$ Department of \\ Respiratory Medicine, Affiliated Hospital \\ of Jilin Medical College, Jilin, Jilin \\ Province, People's Republic of China \\ *These authors contributed equally to \\ this work
}

Background: The exacerbation of chronic obstructive pulmonary disease (COPD) seriously affects the patient's quality of life and prognosis. This multicenter cross-sectional study investigated the characteristics of stable COPD and risk factors for acute exacerbation of COPD (AECOPD) in patients in Changchun, Jilin Province, China.

Methods: The study included 400 outpatients admitted to four secondary hospitals and four tertiary hospitals in Jilin Province from March 2018 to March 2019. Data on the general condition of stable COPD patients, patient self-management, COPD Assessment Test (CAT) scores, number of acute exacerbations in the past 12 months, and medications received during the study period were collected using a questionnaire.

Results: Sociodemographic characteristics and clinical data were obtained from 306 patients, and drug prescription data were obtained from 329 patients. Pearson correlation analysis revealed that CAT scores were positively correlated with the number of acute exacerbations. Age, education level, smoking history, disease duration, number of comorbidities, and the presence of ischemic heart disease (IHD) were associated with AECOPD. Moreover, the level of education, disease duration, and the presence of IHD were independent risk factors for AECOPD. Poor compliance due to the lack of understanding of the disease and the high cost of treatment is a risk factor for AECOPD. In addition, increased air pollution in industrial cities and vitamin D deficiency are closely related to AECOPD.

Conclusion: Low education level, long disease duration, and the presence of IHD may promote the exacerbation and poor control of COPD in patients in Jilin Province.

Keywords: COPD, exacerbation, risk factors, Jilin Province

\section{Introduction}

Chronic obstructive pulmonary disease (COPD) is characterized by chronic inflammation of the airways and has a high prevalence, morbidity, and mortality in many parts of the world. ${ }^{1-4}$ Patients with stable COPD often have acute exacerbation due to risk factors, comorbidities, poor adherence to treatment, and insufficient treatment. AECOPD leads to lung function decline, reduced health-related quality of life, and poor prognosis. ${ }^{5-8}$ In addition, AECOPD has a high economic and social cost and is associated with high morbidity and mortality. ${ }^{9}$ The clinical manifestations and prevalence of COPD are variable, ${ }^{10,11}$ which may be related to differences in the level of economic development between provinces and the degree of exposure to risk factors. ${ }^{12}$ Therefore, further research on the management of COPD is needed to determine disease characteristics and risk factors.
Correspondence: Peng Gao

Department of Respiratory, Second Hospital of Jilin University, Changchun, jilin Province, People's Republic of China $\mathrm{Tel} / \mathrm{Fax}+86-43181136866$

Email gaopeng1234@sina.com
International Journal of Chronic Obstructive Pulmonary Disease 2020:I5 2249-2256 
Jilin Province in northeastern China has a temperate climate and slow economic growth. In addition, coalburning and industrial emissions increase air pollution. Air pollution is a significant contributor to AECOPD. Moreover, most patients with COPD have vitamin D deficiency, ${ }^{13}$ which decreases lung function, ${ }^{14}$ increases the risk of respiratory infections, ${ }^{15,16}$ and may predispose to AECOPD. Long and cold winters in Jilin Province limit outdoor activities and may lead to vitamin D deficiency, which is linked to the clinical worsening of COPD. However, few studies have evaluated the characteristics of COPD and aggravating risk factors in patients in Jilin Province. This study reviews the risk factors for AECOPD in Jilin Province and can serve as a guideline for preventing and treating this disease in this province.

\section{Methods}

\section{Study Design and Patients}

This multicenter cross-sectional study continuously enrolled 400 stable COPD outpatients admitted to four secondary hospitals and four tertiary hospitals in Jilin Province from March 2018 to March 2019.

The inclusion criteria were diagnosis of COPD according to the Global Initiative for Chronic Obstructive Lung Disease (GOLD), airflow limitation defined as forced expiratory volume in one second/forced vital capacity $<70 \%$, disease duration longer than 1 year, and written consent to participate in the investigation. The exclusion criteria were patients with heart, respiratory, or renal failure; current AECOPD; acute cerebrovascular disease with impaired consciousness; terminal cancer; pulmonary embolism; or active tuberculosis. The patients with missing data on COPD diagnosis and treatment, and those unwilling or unable to participate because of mental or neurological illnesses were also excluded. This study was approved by the research ethics committee of the Second Hospital of Jilin University. All patients signed informed consent.

\section{Data Collection}

Demographic and socioeconomic data, including age, gender, BMI (weight $[\mathrm{kg}] /$ height $[\mathrm{m}]^{2}$ ), area of residence (rural or urban), level of education, occupation, and smoking history, were collected using a questionnaire. Clinical data included the number of acute exacerbations in the past 12 months (including acute episodes leading to hospital admission) and comorbidities during the course of the disease. Comorbidities included asthma, bronchiectasis, ischemic heart disease (IHD), chronic cardiac insufficiency, diabetes, and hypertension. The CAT questionnaire contained eight questions with scores ranging from 0 to 5 , and total scores of $0-10,11-20,21-30$, and 31-40 represented mild, moderate, severe, and very severe symptoms, respectively. ${ }^{17}$

\section{Statistical Analysis}

Statistical analysis was performed using SPSS software version 25.0. Continuous variables were presented as mean and standard deviation or percentage and were compared using an independent $t$-test. Categorical variables were analyzed using the Chi-square test. The association between demographic factors, risk factors, and AECOPD was evaluated by univariate analysis. The correlation between potential risk factors and AECOPD was analyzed by logistic regression. P-values of less than 0.05 were considered statistically significant. The associations were expressed as odds ratios (ORs) and 95\% confidence intervals (CIs). The relationship between CAT scores and the number of exacerbations was evaluated using Spearman correlation coefficient. The level of statistical significance was set at $\mathrm{p}<0.05$.

\section{Results}

\section{Sociodemographic Characteristics and Clinical Data}

A total of 400 questionnaires were distributed, and 306 questionnaires were valid. The mean age of our sample was $67.08 \pm 11.41$ years. The baseline characteristics of our cohort are described in Table 1. Approximately $44.44 \%$ of the study population were rural residents, $56.86 \%$ were male, $74.84 \%$ had middle school education or lower, $35.62 \%$ were former smokers, and $35.95 \%$ were current smokers. The mean smoking history was $25.97 \pm 23.42$ pack-years.

Clinical data, including comorbidities, are summarized in Table 2. The most common comorbidities were IHD (39.22\%) and hypertension (27.45\%). Only $26.80 \%$ of COPD patients had no comorbidities.

\section{Risk Factors for AECOPD}

The CAT score was $\leq 10$ in $15.03 \%$ of our sample. After adjusting for smoking status, CAT scores were weakly correlated with the number of acute exacerbations in the past 12 months $(\mathrm{R}=0.394, \mathrm{p}<0.0001)$ (Figure 1). The clinical and demographic characteristics of patients with and without exacerbations are shown in Table 3. Patients with AECOPD were older $(\mathrm{p}=0.0408)$, had longer disease duration 
Table I General and Demographic Data of the Study Population

\begin{tabular}{|c|c|}
\hline Male Gender & $174(56.86 \%)$ \\
\hline \multicolumn{2}{|l|}{ Age (years) } \\
\hline$\leq 40$ & $6(1.96 \%)$ \\
\hline $4 I-60$ & 79 (25.82\%) \\
\hline $6 I-80$ & I $83(59.8 \%)$ \\
\hline$>80$ & $38(12.42 \%)$ \\
\hline \multicolumn{2}{|l|}{ BMI } \\
\hline$<18.5$ & $4 \mathrm{I}(13.4 \%)$ \\
\hline $18.5-24.9$ & $175(57.19 \%)$ \\
\hline$\geq 25$ & $90(29.41 \%)$ \\
\hline \multicolumn{2}{|l|}{ Level of education } \\
\hline Middle school education or lower ( $\leq 9$ years) & $229(74.84 \%)$ \\
\hline High school education (9-12years) & $56(18.3 \%)$ \\
\hline University education or higher ( $>12$ years) & $21(6.86 \%)$ \\
\hline \multicolumn{2}{|l|}{ Occupation } \\
\hline Workers, individuals, other workers & $109(35.62 \%)$ \\
\hline Office, management, and technical staff & 75 (24.5I\%) \\
\hline Service workers & $18(5.88 \%)$ \\
\hline Livestock and poultry industry workers & $104(33.99 \%)$ \\
\hline \multicolumn{2}{|l|}{ Area of residence } \\
\hline Rural & I $36(44.44 \%)$ \\
\hline Urban & $170(55.56 \%)$ \\
\hline \multicolumn{2}{|l|}{ Smoking history } \\
\hline Never & 87 (28.43\%) \\
\hline Former & $109(35.62 \%)$ \\
\hline Current & $110(35.95 \%)$ \\
\hline
\end{tabular}

( $<<0.0001)$, lower education level $(\mathrm{p}=0.0149)$, active smoking history $(\mathrm{p}=0.0474)$, and more comorbidities $(\mathrm{p}=0.0011)$ than the control group. The multivariate analysis showed that university education and higher (OR, 0.29 ; $95 \% \mathrm{CI}, 0.08-0.86$; $\mathrm{P}=0.0340$ ), disease duration of $3-5$ years $(\mathrm{OR}, 3.73 ; 95 \% \mathrm{CI}$, 1.82-7.84; $\mathrm{P}<0.0001$ ), disease duration of $5-10$ years (OR, 7.28; 95\% CI, 3.34-16.59; $\mathrm{P}<0.0001)$, disease duration longer than 10 years (OR, 6.01; 95\% CI, 2.95-12.65; $\mathrm{P}<0.0001$ ), and IHD (OR, 2.01; 95\% CI, 1.05-3.89; $\mathrm{P}=0.0352$ ) were significantly associated with AECOPD (Table 4).

\section{Treatment and Economic Burden of COPD}

A total of 329 of 400 COPD patients answered questions about treatment (Table 5). The prescribed medications were inhaled bronchodilators (214, 65.05\%), inhaled corticosteroids (ICSs) $(213,64.74 \%)$, or oral corticosteroids (OCS) $(113,34.35 \%)$. Of these, 20 $(13.42 \%)$ used inhaled bronchodilators regularly in the
Table 2 Clinical Characteristics of Patients with Chronic Obstructive Pulmonary Disease in Jilin Province, China, Admitted from March 2018 to March 2019

\begin{tabular}{|c|c|}
\hline Variables $(n=306)$ & $\mathbf{N}(\%)$ \\
\hline \multicolumn{2}{|l|}{ Duration of COPD (years) } \\
\hline$\leq 3$ & 89 (29.08\%) \\
\hline $3-5$ & $69(22.55 \%)$ \\
\hline $5-10$ & $59(19.28 \%)$ \\
\hline$\geq 10$ & 89 (29.08\%) \\
\hline \multicolumn{2}{|l|}{ Comorbidities } \\
\hline None & $82(26.80 \%)$ \\
\hline Pulmonary embolism & I (0.33\%) \\
\hline Interstitial lung disease & $9(2.94 \%)$ \\
\hline Bronchiectasis & $29(9.48 \%)$ \\
\hline Tuberculosis sequels & $9(2.94 \%)$ \\
\hline Ischemic heart disease & $120(39.2) 2 \%$ \\
\hline Chronic cardiac insufficiency & $24(7.84 \%)$ \\
\hline Hypertension & $84(27.45 \%)$ \\
\hline Diabetes & $31(10.13 \%)$ \\
\hline Cerebrovascular disease & $13(4.25 \%)$ \\
\hline Anxiety or depression & 9 (2.94\%) \\
\hline \multicolumn{2}{|l|}{ Duration of oxygen therapy (hours per day) } \\
\hline None & $256(83.66 \%)$ \\
\hline$<4$ & $17(5.56 \%)$ \\
\hline $4-8$ & $15(4.9 \%)$ \\
\hline $8-15$ & $16(5.23 \%)$ \\
\hline$>15$ & $2(0.65 \%)$ \\
\hline \multicolumn{2}{|l|}{ Total number of acute exacerbations } \\
\hline None & | 47 (48.04\%) \\
\hline I & $95(31.05 \%)$ \\
\hline 2 & 49 (16.01\%) \\
\hline$\geq 3$ & $15(4.9 \%)$ \\
\hline \multicolumn{2}{|l|}{ COPD Assessment Test scores } \\
\hline $0-10$ & $46(15.03 \%)$ \\
\hline $11-20$ & $123(40.2 \%)$ \\
\hline $21-30$ & $120(39.22 \%)$ \\
\hline $31-40$ & $17(5.56 \%)$ \\
\hline
\end{tabular}

Abbreviation: COPD, chronic obstructive pulmonary disease.

past 12 months, and 19 (11.24\%) used inhaled ICSs or hormones regularly in the past 12 months. The drugs prescribed to patients with and without AECOPD are shown in Table 6.

The cohort was divided into four groups based on the number of acute exacerbations, CAT scores, and hospitalization according to GOLD guidelines (A [N=27], $\mathrm{B}[\mathrm{N}=190], \mathrm{C}[\mathrm{N}=2]$, and $\mathrm{D}[\mathrm{N}=110]) .{ }^{18}$ Group $\mathrm{C}$ was not included in the analysis because of the small sample size. The average monthly cost of treatment of COPD in the study period is shown in Figure 2. 


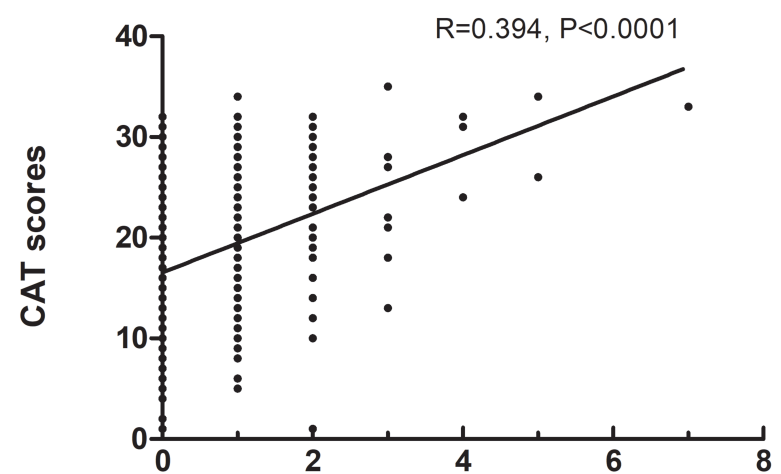

Number of acute exacerbations in the past 12 months

Figure I Association of CAT scores with the number of acute exacerbations of chronic obstructive pulmonary disease in the past 12 months.

\section{Discussion}

This cross-sectional multicenter study analyzed baseline data of patients with stable COPD and the risk factors for AECOPD in Jilin Province, Northeast China. The CAT questionnaire is useful to evaluate health-related quality of life in patients with AECOPD. ${ }^{19}$ CAT scores were weakly correlated with the number of acute exacerbations in the past 12 months (Figure 1). Consistent with our findings, Tu et al demonstrated that the frequency of COPD exacerbation frequency was positively correlated with CAT scores. ${ }^{20}$ Furthermore, frequent exacerbations
Table 4 Multivariate Regression Analysis of Risk Factors for Exacerbation of Stable Chronic Obstructive Pulmonary Disease in Patients in Jilin Province, China, Admitted from March 2018 to March 2019

\begin{tabular}{|l|l|l|l|}
\hline Risk Factors (n=306) & OR & $\mathbf{9 5 \% ~ C I}$ & P-value \\
\hline University education or higher & 0.29 & $0.08-0.86$ & $0.0340^{*}$ \\
\hline Duration of COPD (years) & & & \\
$3-5$ & 3.73 & $1.82-7.84$ & $<0.000 I^{*}$ \\
$5-10$ & 7.28 & $3.34-16.59$ & $<0.000 I^{*}$ \\
$\geq 10$ & 6.01 & $2.95-12.65$ & $<0.000 I^{*}$ \\
Ischemic heart disease & 2.01 & $1.05-3.89$ & $0.0352^{*}$ \\
\hline
\end{tabular}

Notes: The variables considered significant in the univariate analysis were included in the multivariate regression model. The associations were expressed as odds ratio (OR) and $95 \%$ confidence interval $(\mathrm{Cl}) .{ }^{*}<0.05$.

Abbreviation: COPD, chronic obstructive pulmonary disease.

are linked to higher mortality. ${ }^{21}$ However, the correlation between CAT and AECOPD in our study was weak, which might be due to differences in patient age, education level, and patient perception of disease severity. Therefore, whether CAT scores may predict the development of AECOPD is unknown.

AECOPD affects the natural history of the disease ${ }^{7}$ and is associated with age, smoking, comorbidities, number of acute exacerbations, and patients' socioeconomic level. In addition, AECOPD can decrease lung function,

Table 3 Baseline Characteristics and Risk Factors for Acute Exacerbation of Chronic Obstructive Pulmonary Disease in Patients in Jilin Province, China, Admitted from March 2018 to March 2019

\begin{tabular}{|c|c|c|c|c|}
\hline & & \multicolumn{3}{|c|}{ Exacerbations } \\
\hline & & No $(n=|4|)$ & Yes $(n=165)$ & P-value \\
\hline Age & & $65.63 \pm 11.65$ & $68.32 \pm 11.09$ & $0.0408^{*}$ \\
\hline Gender $^{\#}$ & Male & 81 (57.45) & $93(56.36)$ & 0.9403 \\
\hline Educational level $^{\#}$ & Middle school and lower & $99(70.21)$ & I 30 (78.79) & $0.0149 *$ \\
\hline Occupation ${ }^{\#}$ & $\begin{array}{l}\text { Office, management, } \\
\text { and technical staff }\end{array}$ & $37(26.24)$ & $38(23.03)$ & 0.5263 \\
\hline Residence $^{\#}$ & Urban & $83(58.87)$ & $87(52.73)$ & 0.3362 \\
\hline Smoking history ${ }^{\#}$ & Current smoker & 61 (43.26) & $49(29.7)$ & $0.0474 *$ \\
\hline Amount smoked & Pack-years & $24.79 \pm 21.98$ & $27.11 \pm 24.80$ & 0.6197 \\
\hline Duration of COPD & $\leq 3$ years & $67(47.52)$ & $22(13.33)$ & $<0.000 I^{*}$ \\
\hline Number of comorbidities ${ }^{\#}$ & None & $52(36.88)$ & $30(18.18)$ & $0.0011 *$ \\
\hline Ischemic heart disease ${ }^{\#}$ & No & $104(73.76)$ & $82(49.7)$ & $<0.000 I^{*}$ \\
\hline Hypertension ${ }^{\#}$ & No & $98(69.5)$ & $124(75.15)$ & 0.3295 \\
\hline Diabetes $^{\#}$ & No & 129 (91.49) & I 46 (88.48) & 0.4976 \\
\hline Chronic cardiac insufficiency ${ }^{\#}$ & No & $130(92.2)$ & $152(92.12)$ & 0.9999 \\
\hline Asthma ${ }^{\#}$ & No & $119(84.4)$ & $126(76.36)$ & 0.1074 \\
\hline Bronchiectasis ${ }^{\#}$ & No & 127 (90.07) & I50 (90.9I) & 0.9571 \\
\hline
\end{tabular}

Notes: The univariate analysis of the association between demographic and clinical factors and exacerbation of COPD was performed using an independent $t$-test. ${ }^{*}$ Data were analyzed using the Chi-square test. Statistical significance was set at $p<0.05$. ${ }^{*} p<0.05$.

Abbreviation: COPD, chronic obstructive pulmonary disease. 
Table 5 Medications Prescribed to Patients with Chronic Obstructive Pulmonary Disease in Jilin Province, China, Admitted from March 2018 to March 2019

\begin{tabular}{|l|l|}
\hline Medication (n=329) & $\mathbf{N} / \%$ \\
\hline Inhaled bronchodilator & $214 / 65.05 \%$ \\
Inhaled corticosteroid & $213 / 64.74 \%$ \\
Oral corticosteroid & $113 / 34.35 \%$ \\
Theophylline & $119 / 36.17 \%$ \\
Expectorants & $125 / 37.99 \%$ \\
Others & $26 / 7.9 \%$ \\
None & $74 / 22.49 \%$ \\
\hline
\end{tabular}

increase mortality, affect the quality of life, and increase socioeconomic burden. ${ }^{5,9,22,23}$ This study investigates the risk factors for AECOPD to help prevent and treat this disease and improve prognosis.

The main cause of COPD is smoking, ${ }^{24-26}$ which is closely related to a decline in lung function. ${ }^{27}$ Previous studies have shown that smoking cessation can delay lung function decline and improve survival. ${ }^{4}$ However, in our cohort, smoking was not an independent risk factor for AECOPD, which might be due to the small sample size and geographic heterogeneity of the disease.
Previous studies have shown that age is a risk factor for AECOPD,${ }^{28}$ which may be due to the decline in lung function with age. ${ }^{29}$ These findings agree with our study, wherein the risk of exacerbation increased as the disease progressed, probably because of poor lung function and other risk factors such as comorbidities and smoking. In addition, disease duration was an independent risk factor for AECOPD in our cohort.

Comorbidities are common in COPD patients and have a significant impact on patient outcomes, quality of life, and survival. ${ }^{30}$ In our cohort, comorbid diseases were found in 224 patients, and the most common diseases were IHD and hypertension. IHD was an independent risk factor for AECOPD, and the number of comorbidities was positively correlated with the number of acute exacerbations. Furthermore, comorbidities significantly increase the cost of AECOPD treatment. ${ }^{31}$ Therefore, preventing and managing comorbidities are crucial to reduce clinical deterioration, improve prognosis, and reduce disease burden.

In our sample, $78.79 \%$ of patients with exacerbations had junior high school education or less, and this high percentage might be related to the lack of awareness of the disease among individuals with a lower educational level and limited self-management skills. In this respect, Yang

Table 6 Drugs Prescribed to Patients with and without Chronic Obstruction Pulmonary Disease Exacerbation in Jilin Province, China, Admitted from March 2018 to March 2019

\begin{tabular}{|c|c|c|c|c|c|}
\hline \multicolumn{6}{|l|}{ Exacerbations } \\
\hline Medication & & Yes $(n=194)$ & No $(n=135)$ & Total $(n=329)$ & P-value \\
\hline \multirow[t]{2}{*}{ None } & Yes & $13(17.6 \%)$ & $6 \mathrm{I}(82.4 \%)$ & 74 & $<0.0001$ \\
\hline & No & $|8|$ (7I\%) & 74 (29\%) & 255 & \\
\hline \multirow[t]{2}{*}{ Bronchodilator } & Yes & I 50 (70.1\%) & 64 (29.9\%) & 214 & 0.092 \\
\hline & No & 44 (38.3\%) & $7 \mid(61.7 \%)$ & 115 & \\
\hline \multirow[t]{2}{*}{ ICS } & Yes & 149 (70\%) & $64(30 \%)$ & 213 & 0.015 \\
\hline & No & 45 (38.8\%) & $7 \mid(6 I .2 \%)$ & 116 & \\
\hline \multirow[t]{2}{*}{ OCS } & Yes & 77 (68.1\%) & 36 (31.9\%) & 113 & 0.626 \\
\hline & No & 117 (54.2\%) & 99 (45.8\%) & 216 & \\
\hline \multirow[t]{2}{*}{ Theophylline } & Yes & 84 (70.6\%) & 35 (29.4\%) & 119 & 0.706 \\
\hline & No & II 10 (52.4\%) & $100(47.6 \%)$ & 210 & \\
\hline \multirow[t]{2}{*}{ Expectorants } & Yes & 97 (77.6\%) & 28 (22.4\%) & 125 & $<0.0001$ \\
\hline & No & 97 (47.5\%) & 107 (52.5\%) & 204 & \\
\hline \multirow[t]{2}{*}{ Others } & Yes & 177 (58.4\%) & 126 (4I.6\%) & 303 & 0.037 \\
\hline & No & 17 (65.4\%) & 9 (34.6\%) & 26 & \\
\hline
\end{tabular}

Abbreviations: ICS, inhaled corticosteroid; OCS, oral corticosteroid. 


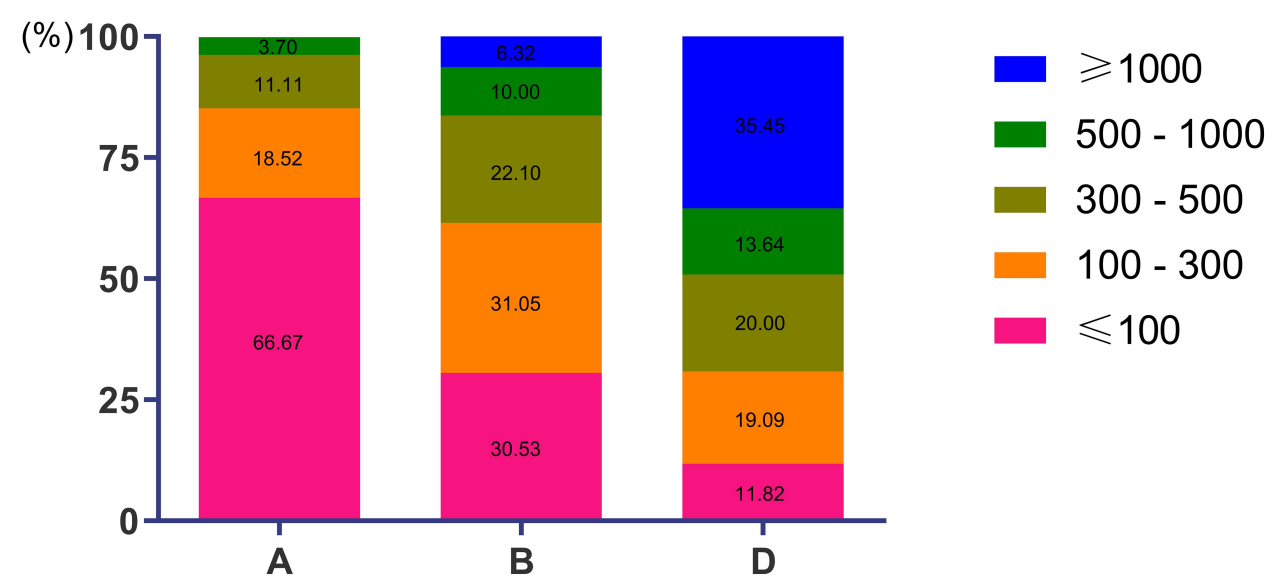

Figure 2 Monthly average cost of diagnosis and treatment of chronic obstructive pulmonary disease (COPD) in patients from groups A, B, and D. (group A, COPD Assessment Test [CAT] score $<10$, number of acute COPD exacerbations in the past 12 months $\leq 1$, and no hospitalizations; group B, CAT score $\geq 10$, number of acute COPD exacerbations in the past 12 months $\leq 1$, and no hospitalizations; group $D, C A T$ score $\geq 10$, number of acute COPD exacerbations in the past 12 months $\geq 2$, and hospitalizations).

et al found that COPD patients with more knowledge about the disease had better self-management, ${ }^{32}$ which is consistent with other studies, demonstrating that increasing awareness about disease management is essential to improve prognosis.

The main drugs prescribed to COPD patients are bronchodilators and ICSs. The most commonly used medications in our cohort were inhaled bronchodilators $(65.05 \%)$ and ICSs (64.74\%).

During the study period, only 20 patients were regularly treated with inhaled bronchodilators, and 19 patients were regularly treated with ICSs, demonstrating that treatment compliance was poor. Poor treatment adherence is common in COPD patients and is a risk factor for AECOPD. ${ }^{33-35}$ Poor compliance is associated with low education, older age, insufficient understanding of the disease, the misuse of inhalers, ${ }^{36}$ and the high cost of COPD treatment. Furthermore, poor adherence may increase mortality, hospitalization, and medical costs, and reduce health-related quality of life. ${ }^{37,38}$ ICSs are widely used in China to treat AECOPD. Compared with glucocorticoids, ICSs have higher local anti-inflammatory activity and produce fewer systemic side effects. Our results showed that $70 \%$ of COPD patients treated with ICS experienced AECOPD. The limited effectiveness of ICSs in our cohort may be due to the small sample size and disease heterogeneity and is worthy of further exploration.

The average cost of treatment of AECOPD in patients from groups A, B, and D was 500-1000 yuan and more than 1000 yuan, showing an upward trend. The cost of hospitalization and drug therapy is higher among patients with AECOPD, which increases economic burden, as demonstrated in other studies. ${ }^{39,40}$ Financial distress, poor treatment compliance, and the lack of understanding of COPD due to low education level may favor the occurrence of exacerbations. However, additional studies are necessary to confirm this hypothesis.

Climate and air pollution play an important role in AECOPD, especially in winter. ${ }^{41,42}$ Because of greenhouse gas emissions from coal combustion, as well as emissions from fuel combustion and industrial activities (there is a large chemical complex in Jilin Province), atmospheric particulate matter (PM) and $\mathrm{PM}_{2.5}$ levels are high in this province. Previous studies have shown that $\mathrm{PM}$ and other air pollutants increase the rate of AECOPD. ${ }^{43,44}$ Therefore, the high prevalence of AECOPD in this province may be due to low temperatures in winter, coal-based heating, and industrial development.

Vitamin D deficiency is common in patients with COPD [13] and is associated with decreased lung function [46] and COPD exacerbation [14], indicating that this deficiency can potentially increase the risk of AECOPD; nonetheless, this relationship needs further investigation.

This study has limitations. First, the sample size was small, and larger studies are necessary to confirm our results. Second, the questionnaire was given to outpatients only, and drug treatment data were incomplete, underscoring the need to increase the number of follow-ups.

\section{Conclusion}

Our research shows that most COPD patients in Changchun, Jilin Province, are older and male, with a history of smoking, lower education level, and comorbidities. Smoking, older 
age, and comorbidities predispose to AECOPD. Other potential contributors to AECOPD are low education, insufficient knowledge of the disease, poor self-management, poor treatment compliance, air pollution, and long and cold winters, which limit outdoor activities and vitamin D synthesis. Notwithstanding, many known risk factors for AECOPD can be changed through patient management. Therefore, increasing awareness and knowledge about COPD and using targeted interventions can improve patient outcomes.

\section{Abbreviations}

COPD, chronic obstructive pulmonary disease; CAT, COPD Assessment Test; $\mathrm{FEV}_{1}$, forced expiratory volume in one second; FVC, forced vital capacity; IHD, ischemic heart disease; OD, odds ratio; ICS, inhaled corticosteroid; OCS, oral corticosteroid; PM, particulate matter.

\section{Data Sharing Statement}

All data generated or analyzed during the study period are included in this article.

\section{Ethics Approval and Consent to Participate}

The study protocol was approved by the research ethics committee of the Second Hospital of Jilin University, and all patients signed informed consent. The study was conducted in accordance with the Declaration of Helsinki.

\section{Author Contributions}

All authors made substantial contributions to conception and design, acquisition of data, or analysis and interpretation of data; took part in drafting the article or revising it critically for important intellectual content; agreed to submit to the current journal; gave final approval of the version to be published; and agree to be accountable for all aspects of the work.

\section{Funding}

This work was funded by the Jilin Province Development and Reform Commission Plan (2019C047-7), the Jilin Province Natural Science Foundation (202000201384JC), the Jilin Provincial Department of Finance, Provincial Talent Project (2019SCZT033), the Jilin Province Medical and Health Personnel Project, and the Jilin Province Health Commission Technology Innovation Plan (2018J046). The study design and manuscript writing complied with the rules of the funding agency.

\section{Disclosure}

The authors declare that they have no competing interests for this work.

\section{References}

1. Rabe KF, Hurd S, Anzueto A, et al. Global strategy for the diagnosis, management, and prevention of chronic obstructive pulmonary disease: GOLD executive summary. Am J Respir Crit Care Med. 2007;176(6):532-555. doi:10.1164/rccm.200703-456SO

2. Vestbo J, Hurd SS, Agustí AG, et al. Global strategy for the diagnosis, management, and prevention of chronic obstructive pulmonary disease: GOLD executive summary. Am J Respir Crit Care Med. 2013;187(4):347-365. doi:10.1164/rccm.201204-0596PP

3. Lopez AD, Shibuya K, Rao C, et al. Chronic obstructive pulmonary disease: current burden and future projections. Eur Respir J. 2006;27 (2):397-412. doi:10.1183/09031936.06.00025805

4. Godtfredsen NS, Lam TH, Hansel TT, et al. COPD-related morbidity and mortality after smoking cessation: status of the evidence. Eur Respir J. 2008;32(4):844-853. doi:10.1183/09031936.00160007

5. Donaldson GC, Seemungal TAR, Bhowmik A, Wedzicha JA. Relationship between exacerbation frequency and lung function decline in chronic obstructive pulmonary disease. Thorax. 2002;57 (10):847-852. doi:10.1136/thorax.57.10.847

6. Miravitlles M, Ferrer M, Pont A, et al. Effect of exacerbations on quality of life in patients with chronic obstructive pulmonary disease: a 2 year follow up study. Thorax. 2004;59(5):387-395. doi:10.1136/ thx.2003.008730

7. Hawkins PE, Alam J, McDonnell TJ, Kelly E. Defining exacerbations in chronic obstructive pulmonary disease. Expert Rev Respir Med. 2015;9(3):277-286. doi:10.1586/17476348.2015.1046438

8. Esteban C, Quintana JM, Moraza J, et al. Impact of hospitalisations for exacerbations of COPD on health-related quality of life. Respir Med. 2009;103(8):1201-1208. doi:10.1016/j.rmed.2009.02.002

9. Buist AS, McBurnie MA, Vollmer WM, et al. International variation in the prevalence of COPD (the BOLD Study): a population-based prevalence study. Lancet (London, England). 2007;370 (9589):741-750. doi:10.1016/S0140-6736(07)61377-4

10. Agusti A, Calverley PMA, Celli B, et al. Characterisation of COPD heterogeneity in the ECLIPSE cohort. Respir Res. 2010;11:122. doi:10.1186/1465-9921-11-122

11. Varmaghani M, Dehghani M, Heidari E, Sharifi F, Moghaddam SS, Farzadfar F. Global prevalence of chronic obstructive pulmonary disease: systematic review and meta-analysis. East Mediterr Health J. 2019;25(1):47-57. doi:10.26719/emhj.18.014

12. Halbert RJ, Natoli JL, Gano A, Badamgarav E, Buist AS, Mannino DM. Global burden of COPD: systematic review and meta-analysis. Eur Respir J. 2006;28(3):523-532. doi:10.1183/ 09031936.06.00124605

13. Janssens W, Bouillon R, Claes B, et al. Vitamin D deficiency is highly prevalent in COPD and correlates with variants in the vitamin D-binding gene. Thorax. 2010;65(3):215-220. doi:10.1136/thx.2009.120659

14. Herr C, Greulich T, Koczulla RA, et al. The role of vitamin D in pulmonary disease: COPD, asthma, infection, and cancer. Respir Res. 2011;12:31. doi:10.1186/1465-9921-12-31

15. Karatekin G, Kaya A, Salihoğlu O, Balci H, Nuhoğlu A. Association of subclinical vitamin D deficiency in newborns with acute lower respiratory infection and their mothers. Eur J Clin Nutr. 2009;63 (4):473-477. doi:10.1038/sj.ejcn.1602960

16. Quraishi SA, Bittner EA, Christopher KB, Camargo CA, Salluh J. Vitamin D status and community-acquired pneumonia: results from the third National Health and Nutrition Examination Survey. PLoS One. 2013;8(11):e81120. doi:10.1371/journal.pone.0081120 
17. Jones PW, Harding G, Berry P, Wiklund I, Chen WH, Kline Leidy N. Development and first validation of the COPD assessment test. Eur Respir J. 2009;34(3):648-654. doi:10.1183/09031936.00102509

18. Vogelmeier CF, Criner GJ, Martinez FJ, et al. Global strategy for the diagnosis, management, and prevention of chronic obstructive lung disease 2017 report. GOLD executive summary. Am J Respir Crit Care Med. 2017;195(5):557-582. doi:10.1164/rccm.201701-0218PP

19. Folch Ayora A, Macia-Soler L, Orts-Cortés MI, Hernández C, SeijasBabot N. Comparative analysis of the psychometric parameters of two quality-of-life questionnaires, the SGRQ and CAT, in the assessment of patients with COPD exacerbations during hospitalization: a multicenter study. Chron Respir Dis. 2018;15(4):374-383. doi:10.1177/1479972318761645

20. Tu Y-H, Zhang Y, Fei G-H. Utility of the CAT in the therapy assessment of COPD exacerbations in China. BMC Pulm Med. 2014;14:42. doi:10.1186/1471-2466-14-42

21. Soler-Cataluña JJ, Martínez-García MA, Román Sánchez P, Salcedo E, Navarro M, Ochando R. Severe acute exacerbations and mortality in patients with chronic obstructive pulmonary disease. Thorax. 2005;60(11):925-931. doi:10.1136/thx.2005.040527

22. Halpin DM, Miravitlles M, Metzdorf N, Celli B. Impact and prevention of severe exacerbations of COPD: a review of the evidence. Int J Chron Obstruct Pulmon Dis. 2017;12:2891-2908. doi:10.2147/ COPD.S139470

23. López-Campos JL, Tan W, Soriano JB. Global burden of COPD. Respirology (Carlton, Vic). 2016;21(1):14-23. doi:10.1111/resp.12660

24. Van Remoortel H, Hornikx M, Langer D, et al. Risk factors and comorbidities in the preclinical stages of chronic obstructive pulmonary disease. Am J Respir Crit Care Med. 2014;189(1):30-38.

25. Siafakas NM, Vermeire P, Pride NB, et al. Optimal assessment and management of chronic obstructive pulmonary disease (COPD). The European Respiratory Society Task Force. Eur Respir J. 1995;8 (8):1398-1420. doi:10.1183/09031936.95.08081398

26. The COPD Guidelines Group of the Standards of Care Committee of the BTS. BTS guidelines for the management of chronic obstructive pulmonary disease. Thorax. 1997;52(Suppl 5):S1-28. doi:10.1136/ thx.52.suppl_5.1

27. Kerstjens HA, Rijcken B, Schouten JP, Postma DS. Decline of FEV1 by age and smoking status: facts, figures, and fallacies. Thorax. 1997;52(9):820-827. doi:10.1136/thx.52.9.820

28. Montserrat-Capdevila J, Godoy P, Marsal JR, Barbé F, Galván L. Risk of exacerbation in chronic obstructive pulmonary disease: a primary care retrospective cohort study. BMC Fam Pract. 2015;16:173. doi:10.1186/s12875-015-0387-6

29. Mercado N, Ito K, Barnes PJ. Accelerated ageing of the lung in COPD: new concepts. Thorax. 2015;70(5):482-489. doi:10.1136/ thoraxjnl-2014-206084

30. Smith MC, Wrobel JP. Epidemiology and clinical impact of major comorbidities in patients with COPD. Int J Chron Obstruct Pulmon Dis. 2014;9:871-888. doi:10.2147/COPD.S49621

31. Deniz S, Şengül A, Aydemir Y, Çeldir Emre J, Özhan MH. Clinical factors and comorbidities affecting the cost of hospital-treated COPD. Int J Chron Obstruct Pulmon Dis. 2016;11:3023-3030. doi:10.2147/COPD.S120637
32. Yang H, Wang H, Du L, Wang Y, Wang X, Zhang R. Disease knowledge and self-management behavior of COPD patients in China. Medicine. 2019;98(8):e14460. doi:10.1097/MD.0000000000014460

33. George J, Kong DCM, Stewart K. Adherence to disease management programs in patients with COPD. Int J Chron Obstruct Pulmon Dis. 2007;2(3):253-262.

34. Bourbeau J, Bartlett SJ. Patient adherence in COPD. Thorax. 2008;63 (9):831-838. doi:10.1136/thx.2007.086041

35. Vetrano DL, Bianchini E, Onder G, et al. Poor adherence to chronic obstructive pulmonary disease medications in primary care: role of age, disease burden and polypharmacy. Geriatr Gerontol Int. 2017;17 (12):2500-2506. doi:10.1111/ggi.13115

36. Duarte-de-Araújo A, Teixeira P, Hespanhol V, Correia-de-Sousa J. COPD: understanding patients' adherence to inhaled medications. Int J Chron Obstruct Pulmon Dis. 2018;13:2767-2773. doi:10.214 7/COPD.S160982

37. Vestbo J, Anderson JA, Calverley PMA, et al. Adherence to inhaled therapy, mortality and hospital admission in COPD. Thorax. 2009;64 (11):939-943. doi:10.1136/thx.2009.113662

38. van Boven JFM, Chavannes NH, van der Molen T, Rutten-van Mölken MPMH, Postma MJ, Vegter S. Clinical and economic impact of non-adherence in COPD: a systematic review. Respir Med. 2014;108(1):103-113. doi:10.1016/j.rmed.2013.08.044

39. Perera PN, Armstrong EP, Sherrill DL, Skrepnek GH. Acute exacerbations of COPD in the United States: inpatient burden and predictors of costs and mortality. Copd. 2012;9(2):131-141. doi:10.3109/ 15412555.2011.650239

40. Germini F, Veronese G, Marcucci M, et al. COPD exacerbations in the emergency department: epidemiology and related costs. A retrospective cohort multicentre study from the Italian Society of Emergency Medicine (SIMEU). Eur J Intern Med. 2018;51:74-79. doi:10.1016/j.ejim.2018.01.010

41. Jenkins CR, Celli B, Anderson JA, et al. Seasonality and determinants of moderate and severe COPD exacerbations in the TORCH study. Eur Respir J. 2012;39(1):38-45. doi:10.1183/09031936.00 194610

42. Tseng C-M, Chen Y-T, Ou S-M, et al. The effect of cold temperature on increased exacerbation of chronic obstructive pulmonary disease: a nationwide study. PLoS One. 2013;8(3):e57066. doi:10.1371/journal.pone. 0057066

43. Ding P-H, Wang G-S, Guo Y-L, Chang S-C, Wan G-H. Urban air pollution and meteorological factors affect emergency department visits of elderly patients with chronic obstructive pulmonary disease in Taiwan. Environ Pollut. 2017;224:751-758. doi:10.1016/j. envpol.2016.12.035

44. de Miguel-díez J, Hernández-Vázquez J, López-de-Andrés A, Álvaro-Meca A, Hernández-Barrera V, Jiménez-García R. Analysis of environmental risk factors for chronic obstructive pulmonary disease exacerbation: a case-crossover study (2004-2013). PLoS One. 2019;14(5):e0217143. doi:10.1371/journal.pone.0217143

\section{Publish your work in this journal}

The International Journal of COPD is an international, peer-reviewed journal of therapeutics and pharmacology focusing on concise rapid reporting of clinical studies and reviews in COPD. Special focus is given to the pathophysiological processes underlying the disease, intervention programs, patient focused education, and self management protocols. This journal is indexed on PubMed Central, MedLine and CAS. The manuscript management system is completely online and includes a very quick and fair peer-review system, which is all easy to use. Visit http://www.dovepress.com/testimonials.php to read real quotes from published authors. 